\title{
Stroke Awareness in the General Population: A Study from Jordan
}

\author{
Saba S Madae'en ${ }^{1 *}$, Nailya $\mathbf{R}$ Bulatova ${ }^{1}$, Tahanie A Al-Qhewii ${ }^{2}$, Lina $\mathbf{H}$ \\ Sakran ${ }^{1}$, Hadeel H El-Zayyat ${ }^{2}$, Maisa K Abu Kamar ${ }^{1}$, Hiyam S Al-Haqeesh ${ }^{2}$ and \\ Abdallah M Younes ${ }^{3}$ \\ ${ }^{1}$ Department of Biopharmaceutics and Clinical Pharmacy, Faculty of Pharmacy, The University of Jordan, Amman, 11942, \\ ${ }^{2}$ Department of Pharmacy, Royal Medical Services, ${ }^{3}$ Jordan-Amman Private Clinic, Amman- Jordan.
}

*For correspondence: Email: s.madain@ju.edu.jo; Tel: 0962795466800

Revised accepted: 9 October 2013

\begin{abstract}
Purpose: To assess the awareness level of the Jordanian general population regarding the definition, risk factors, signs and symptoms, and consequences of stroke.

Methods: This was a cross-sectional study. The questionnaire was handed to participants by trained students, the participants were chosen randomly from public places, and the questionnaire used is subdivided into demographic data, questions of multiple choices to identify symptoms and signs, the definition of stroke, and risk factors of stroke. The data were entered and analysed by SPSS software version 16.using frequencies, Chi square and logistic regression. A level of significance of 0.05 was applied.

Results: At least 1993 questionnaires were returned. Out which 40 were excluded for poor quality and 99 were excluded due to missing data. From the 1854 questionnaire used, $82 \%$ were residents of Amman, and only $17 \%$ were older than 47 years of age. Females were almost equally represented as males, who accounted for $57 \%$ of the total. More than $70 \%$ had an educational level higher than secondary school.. Only $1.5 \%$ experienced a previous stroke, and a relatively high proportion (63.8\%) knew someone who suffered from stroke. The most recognized symptom was speech loss (54.7\%). All other symptoms were recognized by $<50 \%$ of the population. Seventy five percent knew that the brain is the organ involved in stroke while $85 \%$ would contact the ambulance on noticing stroke signs, even if symptoms subsequently improved. In a bivariate logistic regression, no independent variables had true effect on knowledge.

Conclusion: We concluded from the study that there are serious gaps in knowledge regarding stroke; an educational program on stroke may help reduce the stroke burden in Jordan.
\end{abstract}

Keywords: Stroke, Awareness, Jordan.

Tropical Journal of Pharmaceutical Research is indexed by Science Citation Index (SciSearch), Scopus, International Pharmaceutical Abstract, Chemical Abstracts, Embase, Index Copernicus, EBSCO, African Index Medicus, JournalSeek, Journal Citation Reports/Science Edition, Directory of Open Access Journals (DOAJ), African Journal Online, Bioline International, Open-J-Gate and Pharmacy Abstracts

\section{INTRODUCTION}

Stroke is a major cause of death and disability worldwide; In Jordan, heart disease and stroke accounted for $>35 \%$ of total deaths in 2005 [1]. A crude estimate suggests that approximately 1 to 3 million people in Jordan will have diabetes, hypertension, or high blood cholesterol by 2050 depending on changes in disease prevalence and the growth of the population [1]. Since these conditions are known to be stroke risk factors, 
we can assume that stroke prevalence will also rise in the nearest future.

Current European Stroke Organization guidelines provide a very narrow time window for the administration of fibrinolytic agents (up to 4.5 hours) in ischemic strokes to rescue the ischemic area in the brain [2]. This practice must be performed in specialized stroke units/centers. A stroke center with a staff complement of fulltime neurologists and a team specialized in cerebrovascular diseases where they can reduce the delays and increase treatment with intravenous tissue plasminogen activator (TPA), was recently established in Jordan. Thus, it is vitally important to have the general population aware of early manifestations of stroke in order to seek medical attention early enough.

To achieve an effective educational health program, it is necessary to identify the target population with low stroke awareness [3]. Many studies on stroke awareness have been conducted worldwide, giving an idea on the degree of knowledge in different parts of the world [4-12] and some went a step ahead in showing the factors that contributed to low knowledge and the best source of information for this population[4,5,7-13].

\section{METHODS}

\section{Study population and questionnaire}

This was a cross-sectional study conducted through a questionnaire given to randomly picked individuals in public places (universities, shopping malls, restaurants, etc). The interview was done in a face to face manner after taking a verbal consent from the participant by well trained PharmD students at Jordan University, and supervised by authors.

Inclusion criteria were adults $>16$ years of age, and a Jordanian resident. Exclusion criteria were severe mental illness, visual or hearing disability that may interfere with answering the questions.

The instrument used was developed from The Stroke Questionnaire [14] and literature review done by the authors, which was translated into Arabic according to the guidelines of the Institute for Health and Care Research Questionnaires Selecting Translating and Validating [15].

In brief, translation of the questionnaire from English into Arabic consisted of a two step process. First two separate forward translations by translators who are native speakers of Arabic and then two separate back translations by translators who are native speakers of the source language, English. It was then corrected and edited by the authors of the paper. The translation produced a questionnaire which was not only comparable in terms of language, but, in particular, is conceptually comparable as well. Questions were transformed into multiple choice questions. After this, fifty questionnaires were piloted in a face to face manner, and the questionnaire was modified as necessary by the authors.

The questionnaire is subdivided into:

1. Demographic data (living area, age, gender, educational level, marital status, health current status, employment status).

2. Experience regarding stroke (Did you suffer stroke or know someone who suffered stroke, How do you rate your knowledge about stroke). This part was added to make sure that personal experience is used as a co-variant in analysis to exclude it as a confounder.

3. Questions regarding signs and symptoms of stroke included 5 options, and signs of stroke were listed along with other 5 options that are not related to stroke, so the participant can choose from them; one or more correct answer was considered as being aware of signs and symptoms.

4. Questions regarding the organ involved in stroke included 8 options; anyone who picked the option that the brain is the organ involved in stroke was considered as identifying a correct answer.

5. Questions regarding risk factors of stroke 14 of 20 options were correct risk factors of stroke; one or more risk factors of stroke identified was considered as being aware of risk factors.

6. Questions regarding consequences were added to the questionnaire: 9 out of 16 options were correct consequences of stroke.

7. Regarding the question "What would you do in a case of suspected stroke" was added to the questionnaire; there were 4 possible options, and the correct one was calling the ambulance even if symptoms improve.

\section{Data entry and statistical analysis}

Descriptive analysis was carried including frequencies and Chi square. Awareness about stroke definition and signs and symptoms were analyzed in accordance to gender, educational level and age. For determination of the independent risk factors of poor knowledge, we 
used logistic regression and backward deletion to get to the best model. A level of significance of 0.05 was used. Data were entered and analyzed using SPSS software, version 16.

\section{RESULTS}

A total of 1993 questionnaires were collected out of which 40 were excluded for poor quality and 99 were excluded as a result of missing data. Out of the 1854 questionnaire used, 82\% were residents in Amman, and only $17 \%$ were older than 47 years of age. Females were almost equally represented as males who accounted for $57 \%$ of the total. More than $70 \%$ had an educational level higher than secondary school. Only $1.5 \%$ experienced a previous stroke, and a relatively high percent of 63.8 knew someone who suffered from stroke. (Table 1).

We further analyzed the factors that may affect awareness regarding the brain as the organ involved in stroke and regarding signs and symptoms of stroke according to gender, educational level, and age.

Table 1: Demographic data
Referring to table 4 that shows the association in Chi-square, gender and educational level have a non significant difference in both awareness regarding the brain as the organ involved in stroke and regarding signs and symptoms of stroke, but we can notice that they were statistically significant in the cases of age $>47$ years with the awareness regarding the brain as the organ involved in stroke and regarding signs and symptoms of stroke, but when looking at the actual difference in percentages, we noticed it was not meaningful.

As shown in Table 2, 75\% of the participants identified the brain as the organ involved in stroke. Sudden loss of speech was the most identified symptom of stroke by a $(54.7 \%)$, sudden weakness of one side of the body by $(49.1 \%)$ followed by headache with neck stiffness and vomiting (36.6\%). The most commonly recognized risk factors of stroke were getting older $(58.8 \%)$, previous stroke $(56.6 \%)$, hypertension (56\%) and smoking (47.5\%). Loss of ability to speak (62\%), loss of ability to walk $(52.6 \%)$ and one-sided paralysis (50\%) were the most recognized consequences of stroke.

\begin{tabular}{|c|c|c|}
\hline Living area & Frequency (\%) & Number \\
\hline Amman & 81.9 & 1518 \\
\hline Province & 18.1 & 336 \\
\hline \multicolumn{3}{|l|}{ Age (yrs) } \\
\hline $16-18$ & 6.4 & 118 \\
\hline $19-25$ & 39.2 & 727 \\
\hline $26-35$ & 21.0 & 389 \\
\hline $36-46$ & 16.8 & 311 \\
\hline $47-57$ & 10.8 & 201 \\
\hline $58-68$ & 4.7 & 87 \\
\hline Over 69 & 1.1 & 20 \\
\hline \multicolumn{3}{|l|}{ Marital status } \\
\hline Single & 52 & 964 \\
\hline Married & 44 & 817 \\
\hline Separated & 2.3 & 42 \\
\hline Other & 1.6 & 29 \\
\hline \multicolumn{3}{|l|}{ Gender } \\
\hline Male & 43.5 & 807 \\
\hline Female & 56.5 & 1047 \\
\hline \multicolumn{3}{|l|}{ Educational level } \\
\hline High School & 24.9 & 461 \\
\hline Bachelor degree & 55.8 & 1034 \\
\hline Higher education (PhD, MS.) & 8.3 & 153 \\
\hline Medical or Nursing degree & 4.7 & 88 \\
\hline No formal education & 2.7 & 50 \\
\hline Diploma & 1.2 & 22 \\
\hline Other educational levels & 2.4 & 44 \\
\hline \multicolumn{3}{|l|}{ Personal stroke experience } \\
\hline $\begin{array}{l}\text { Knowing someone who suffered } \\
\text { from stoke }\end{array}$ & 63.8 & 1183 \\
\hline $\begin{array}{l}\text { Having history of stroke or TIA } \\
\text { Number of participants were } 1854\end{array}$ & 1.5 & 27 \\
\hline
\end{tabular}


Table 3 shows the answers to the question regarding the action taken in case of suspected stroke. About $85 \%$ responded that they would contact the ambulance on signs and symptoms appearance even if the symptoms improve.

For greater clarity, we determined the proportion of people who identified 1 - 5 signs and symptoms and found that $12.7 \%$ identified none; $27.7 \%$ identified only one correct sign or symptom; $31.6 \%$ (the highest) identified 2 correct signs or symptoms; $17.6 \%$ identified 3 correct signs or symptoms; $7.8 \%$ identified 4 correct signs or symptoms of 5 , and only $2.5 \%$ identified all 5 correct signs or symptoms (Table 4). The logistic regression analysis did not indicate any significant relationship between the awareness level and age or educational levels (Table 5).
This study reports awareness of the Jordanian population regarding brain as the organ involved, signs and symptoms and risk factors of cerebrovascular events as well as the appropriate action in case of suspected stroke. In addition factors associated with stroke awareness were investigated.

The Jordanian population had quite a high level of awareness regarding at least one sign or symptom of stroke $(87.3 \%)$. However, only $(2.5 \%)$ were aware of all the manifestations of the disease. The knowledge of the Jordanian population in identifying the brain as the main organ of stroke was higher compared to Omani

\section{DISCUSSION}

Table 2: Awareness regarding brain as the organ involved in stroke, symptoms, risk factors, and consequences of stroke

\begin{tabular}{|c|c|c|}
\hline Stroke organ involved & Frequency (\%) & Number \\
\hline The brain is the organ involved in stroke. & 75.0 & 1393 \\
\hline \multicolumn{3}{|l|}{ Symptoms of stroke } \\
\hline Sudden loss of speech & 54.7 & 1015 \\
\hline Sudden weakness on one side of the body & 49.1 & 910 \\
\hline Headache with neck stiffness and vomiting & 36.6 & 679 \\
\hline Sudden onset of vertigo & 30.3 & 562 \\
\hline Sudden loss of eyesight in one eye & 23 & 427 \\
\hline \multicolumn{3}{|l|}{ Risk factors of stroke } \\
\hline Getting older & 58.8 & 1090 \\
\hline Previous stroke & 56.6 & 1030 \\
\hline Hypertension & 56 & 1038 \\
\hline Smoking cigarettes & 47.5 & 881 \\
\hline Family history of stroke & 46.3 & 858 \\
\hline Hypercholesterolemia & 42 & 779 \\
\hline Family history of CVD and DM & 38.8 & 720 \\
\hline Obesity & 36.9 & 684 \\
\hline Personal history of heart disease & 32 & 594 \\
\hline Diabetes & 30.5 & 565 \\
\hline Excessive alcohol intake & 29 & 539 \\
\hline Stress & 27.5 & 510 \\
\hline Being male & 16.6 & 297 \\
\hline \multicolumn{3}{|l|}{ Consequences of stroke } \\
\hline Loss of ability to speech & 62 & 1211 \\
\hline Loss of ability to walk & 52.6 & 1028 \\
\hline One sided paralysis & 50 & 977 \\
\hline Loss of sight & 35.7 & 698 \\
\hline Loss of ability to hear & 28.7 & 561 \\
\hline Relearning necessity & 14.4 & 282 \\
\hline
\end{tabular}

The statements listed above are the ones identified as correct;

$C V D=$ cardiovascular disease $; D M=$ diabetes mellitus

Table 3: Action in case of a suspected stroke

\begin{tabular}{lll}
\hline Action to be taken & $\begin{array}{l}\text { Frequency } \\
\text { (\%) }\end{array}$ & Number \\
\hline Contact the ambulance even if the symptoms improve & 84.8 & 1657 \\
Contact the doctor even if the symptoms improve & 14.9 & 291 \\
Contact the relatives/ neighbors even if the symptoms improve & 5.7 & 112 \\
\hline
\end{tabular}


Table 4: Chi-Square: Factors that may affect awareness regarding the brain as the organ involved in stroke, and signs and symptoms of stroke

\begin{tabular}{|c|c|c|c|c|}
\hline Variable & $\begin{array}{l}\text { Identified one of } \\
\text { the symptoms and } \\
\text { signs (\%) }\end{array}$ & P-value & $\begin{array}{l}\text { Identified brain } \\
\text { involvement }(\%)\end{array}$ & P-value \\
\hline \multicolumn{5}{|l|}{ Age } \\
\hline Male & 86.5 & 0.56 & 74.71 & 0.682 \\
\hline Female & 87.4 & & 75.51 & \\
\hline \multicolumn{5}{|l|}{ Age } \\
\hline$<47$ years & 86.1 & 0.01 & 74.3 & 0.039 \\
\hline$>47$ years & 91.6 & & 79.8 & \\
\hline \multicolumn{5}{|l|}{ Educational level } \\
\hline Lower than secondary school & 84.9 & 0.076 & 73.9 & 0.401 \\
\hline Higher than secondary school & 87.9 & & 75.7 & \\
\hline
\end{tabular}

Table 5: Bivariate logistic regression: independent predictors of knowledge about brain involvement and warning symptoms of stroke

\begin{tabular}{|c|c|c|c|c|c|c|}
\hline Variables & $\begin{array}{l}\text { Symptoms } \\
\text { \& signs } \\
\text { Odd's ratio }\end{array}$ & $95 \% \mathrm{Cl}$ for OR & $\begin{array}{l}P \text { - } \\
\text { value }\end{array}$ & $\begin{array}{l}\text { Brain } \\
\text { involvement } \\
\text { Odd's ratio }\end{array}$ & $95 \% \mathrm{Cl}$ for OR & $P$-value \\
\hline Being Female & 1.098 & $0.835-1.445$ & 0.91 & 1.061 & $0.856-1.314$ & 0.586 \\
\hline $\begin{array}{l}\text { Age older than } 47 \\
\text { years old }\end{array}$ & 1.805 & $1.176-2.770$ & 0.007 & 1.396 & $1.031-1.890$ & 0.031 \\
\hline $\begin{array}{l}\text { Education higher } \\
\text { than secondary } \\
\text { school }\end{array}$ & 1.338 & $1.004-1.782$ & 0.05 & 1.12 & $0.892-1.410$ & 0.326 \\
\hline
\end{tabular}

(34.8\%) [4], Pakistani (50.8\%) [5], and Indian population $(45.5 \%)$ [9]. The results were comparable to those of the Australian population $(76 \%)[12]$.

The most commonly identified symptom of stroke was sudden loss of speech $(54.7 \%)$ as in some studies in Ireland (54\%) [6] and Australia $(60.1 \%)$ [12], but note the other studies where sudden weakness of one side of the body was the most identified symptom in the Omani (65\%) [4] and Nigerian population (55\%) [13].

In other studies, hypertension was the most recognized risk factor, for example, in Oman $(34.5 \%)$ [4], Ireland (75\%) [6], India (45.1\%) [9], and Pakistan (69.2\%) [5].

\section{Limitations of the study}

The results on stroke awareness might have been overestimated due to the fact that the questionnaire used multiple-choice questions in which limited options are available to study participants and he/she can guess the answer, unlike open-ended questions [16]. The review of 39 studies exploring knowledge and awareness of stroke by Jones et al [16] showed a difference between the studies that used open-ended questions and those who used multiple-choice questions. The identification of stroke symptoms and risk factors was poor in open-ended questions. It is better to use partially-aided questions in order to better simulate real life situations of stroke.

\section{CONCLUSION}

Although the general population awareness about stroke was high, some gaps in knowledge still exist, which may result in the late arrival of patients with stroke at specialized facilities thus delaying treatment [17]. Educational programs at the community level involving mass media, schools, universities and governmental agencies are needed in order to improve stroke awareness among the Jordanian population.

\section{CONFLICT OF INTEREST}

The authors declare that there are no conflicts of interest.

\section{FUNDING}

There was no external funding for this research.

\section{ACKNOWLEDGMENT}

Special thanks for Dr Sayel Madae'en for reviewing the manuscript. 


\section{REFERENCES}

1. Brown DW, Mokdad AH, Walke H, As'ad M, Al-Nsour M, Zindah M, Arqoob K, Belbeisi A. Projected burden of chronic, noncommunicable diseases in Jordan [letter]. Prev Chronic Dis. 2009: 6

2. The European Stroke Organisation (ESO) Executive Committee and the ESO Writing Committee: Guidelines for management of ischaemic stroke and transient ischaemic attach. Cerebrovasc Dis. 2008; 25: 457-507.

3. Lecouturier J, Rodgers $H$, Murtagh M, White M, Ford G, Thomson $R$. Systematic review of mass media interventions designed to improve public recognition of stroke symptoms, emergency response and early treatment. BMC Public Health. 2010; 10: 784.

4. Al Shafee MA, Ganguly SS, Al Asmi AR. Perception of stroke and knowledge of potential risk factors among Omani patients at increased risk for Stroke. BMC Neurol. 2006; 6: 38.

5. Aly Z, Abbas K, Kazim SF, Taj F, Aziz F, Irfan A, Sheikh $R$, Shakir M, Javed SM, Fatmi Z, Awareness of stroke risk factors, signs and treatment in a Pakistani population. J Pak Med Assoc. 2009; 7: 59; 495-499.

6. Hickey A, O'Hanlon1 A, McGee H, Donnellan C, Shelley $E$, Horgan F, and O'Neill A, Stroke awareness in the general population: knowledge of stroke risk factors and warning signs in older adults. BMC Geriatr. 2009; 9: 35

7. Kraywinkel K, Heidrich J, Heuschmann PV, Wagner M, Berger $K$, Stroke risk perception among participants of a stoke awareness campaign. BMC Public Health. 2007; 7: 39.

8. El sherbiny $N$, Hadeer M, Ghaffan A, El Monsly D, Stroke knowledge and awareness among hospital workers in fayoum university. J Am Sci. 2011; 7(12): 68-72.

9. Pandian JD, Jaison A, Deepak SS, Kalra G, Shamsher S, Lincoln DJ, Abraham G. Public awareness of warning symptoms, risk factors and treatment of stroke in Northwest India. Stroke. 2005; 36: 644648.

10. Parahoo K, Thompson K, Cooper M, Stringer M, Ennis E, McCollam P. Stroke: Awareness of the signs, symptoms and risk factors - A population-based survey. Cerebrovasc Dis. 2003; 16(2): 134-140.

11. Reeves MJ, Hogan JG, Rafferty A. Knowledge of stroke risk factors and warning signs among Michigan adults. Neurology. 2002; 59: 1547-1552.

12. Sug Yoon S, Heller RF, Levi C, Wiggers J, Fitzgerald $P E$. Knowledge of stroke risk factors, warning symptoms, and treatment among an Australian urban population. Stroke. 2001; 32: 1926-1930.

13. Wahab KW, Okokhere PO, Ugheoke AJ, Oziegbe O, Asalu AF, Salami TA. Awareness of warning signs among suburban Nigerians at high risk for stroke is poor: A cross-sectional study. BMC Neurol. 2008; 8: 18.

14. Stroke Awareness Questionnaire on the internet [cited 2010 Dec 20] Available from http://www.leicesters hospitals.nhs.uk/aboutus/departments-services/ stroke-services/leicester-stroke-awarenesscampaign/stroke-questionnaire/

15. The Institute for Health and Care Research Questionnaires: Selecting Translating and Validating V1.0 1 Jan 2010, Translation into English and updated on the internet [cited 2010 Nov 9] Available from http://www.emgo.nl kc/preparation/research\%20design/8\%20Question naires\%20selecting, \%20translating\%20and\%20val idating.html

16. Jones $S P$, Jenkinson AJ, Leathley MJ, Watkins $C L$. Stroke knowledge and awareness: an integrative review of the evidence. Age Ageing. 2010; 39: 1122.

17. Bercker K, Fruin M, Gooding T, Tirschwell D, Love P, Mankowski T. Community- based education improves stroke knowledge. Cerebrovasc Dis. 2001; 11 (1): 34-34 